\title{
Origin and Effects of Impurities in High Purity Gold ${ }^{1}$
}

\author{
David J Kinneberg and Stephen $R$ Williams \\ Metalor USA Refining Corporation, PO Box 255, North Attleborough, Mass., USA \\ and D P Agarwal \\ Leach and Garner Company, PO Box 200, North Attleborough, Mass., USA
}

\begin{abstract}
Chemical specifications for high purity gold have grown increasingly stringent as manufacturers strive to improve quality control. Once 999.9-fine grain and bullion bars were accepted without question; today sophisticated users insist on knowing impurity levels or, at least, the source of the gold. This paper demonstrates why. Using glow discharge mass spectrometry, concentrations of seventeen elements were measured in hallmarked bullion bars and grain from different sources. In 89 percent of the samples, gold bullion met or exceeded hallmarked purities. As expected, the principal impurity was silver followed by iron, copper and lead. At surprisingly low levels, some impurities can impact manufacturing processes, resulting in hard spots, embrittlement, blistering, and discoloration. After reviewing why various impurities are not entirely removed by the prevalent refining processes, this paper examines the effect of the significant impurities on manufacturing processes. Since the only means of dealing with excessive impurity levels is to refine contaminated metal, we conclude that manufacturers are exercising reasonable prudence by carefully evaluating incoming gold bullion in order to hold down overall production costs.
\end{abstract}

Markets for gold bullion are robust and diverse; a wide array of choices is available to purchasers of gold bullion for jewelry manufacture. Commodity products range in purity from 995-fine 'good delivery' bars to kilobars and grain hallmarked at 999.9 fineness. (Fineness refers to gold content measured in parts per thousand; a fineness of 999.9 equals 99.99 per cent gold.) The option also exists for higher purities or bullion purchased against a company specification. Each of these products carries its own availability and price, on top of the usual variations in the market value of the gold.

How should a purchaser respond? On the one hand, lower grades (less than 999.5 fine) command little or no premium and are generally more readily available. On the other hand, while the gold content of bullion is precisely known, what else is present that could lead to manufacturing difficulties? Just how serious is the risk of impurities disrupting the manufacturing process or compromising product quality?

The purpose of this paper is to provide information on the quality of gold bullion. Since 999.9-fine gold has become the standard in the marketplace, we focus on this commodity. What are the impurities in 999.9-fine gold and where do they originate? Which refining processes result in the lowest concentrations of impurities? And most important of all, which impurities carry the highest risk of disrupting a manufacturing operation? These are the questions we address as we explore whether buyers should purchase against a clearly defined specification of impurity levels or be content with a simple measurement of gold content. After all, 999.9 is almost 1000 - are further specifications warranted?

\section{CLASSIFICATION OF IMPURITIES}

A natural starting point for discussing impurities in gold bullion is ASTM Specification B-562, the only widely accepted criteria for high-purity gold bullion. (This is not to say that ASTM B-562 is widely used in

\footnotetext{
1 This article is based on a presentation given at the Santa Fe Symposium on Jewelry Manufacturing Technology, 1997
} 
the industry as a purchasing specification; to enhance liquidity, bullion sellers and traders generally resist efforts to characterize impurities.) Table 1 summarizes impurity levels by bullion grade. At the low end of the spectrum, 99.5 grade (995 parts per thousand) simply requires a minimum gold content. This is the only grade that actually requires that the gold content be measured; gold contents for the other grades are calculated by difference. Five elements are considered in the specification of 999.5-fine gold. These include three elements commonly used as alloying agents (silver, copper and palladium) that will probably be added during manufacturing anyway. The other two elements, iron and lead, are recognized as having serious consequences during processing. The number of specified elements increases substantially in the 99.99 grade; thirteen elements are listed, from arsenic, bismuth and chromium to nickel, manganese and magnesium and ending with silicon and tin. Of course, the five elements of the 99.95 grade are included as well. Surprisingly, the list decreases in going to the 99.995 grade - arsenic and nickel are dropped. (For reference, Figure 1 graphically compares the magnitude of impurity levels by bullion grade.)

Now that the elements specified in ASTM B-562 have been presented, something must be said about the omissions. Platinum, a common impurity in gold, is not listed, presumably because it has a higher monetary value than gold and confers few deleterious effects during manufacturing. Other platinum group metals, rhodium, ruthenium, osmium and iridium, are also not specified, nor are any of the classic non-metallic

Table 1 Chemical requirements for gold bullion as given by ASTM B-562

\begin{tabular}{lcccc} 
& \multicolumn{5}{c}{ Concentration, $\mathbf{m g} / \mathbf{k g}$} \\
Gold Grade (\%) & 99.5 & 99.95 & 99.99 & 99.995 \\
Silver & - & 350 & 90 & 10 \\
Copper & - & 200 & 50 & 10 \\
Palladium & - & 200 & 50 & 10 \\
Iron & - & 50 & 20 & 10 \\
Lead & - & 50 & 20 & 10 \\
Silicon & - & - & 50 & 10 \\
Magnesium & - & - & 30 & 10 \\
Arsenic & - & - & 30 & - \\
Bismuth & - & - & 20 & 10 \\
Tin & - & - & 10 & 10 \\
Chromium & - & - & 3 & 3 \\
Nickel & - & - & 3 & - \\
Manganese & - & - & 3 & 3 \\
& & & &
\end{tabular}

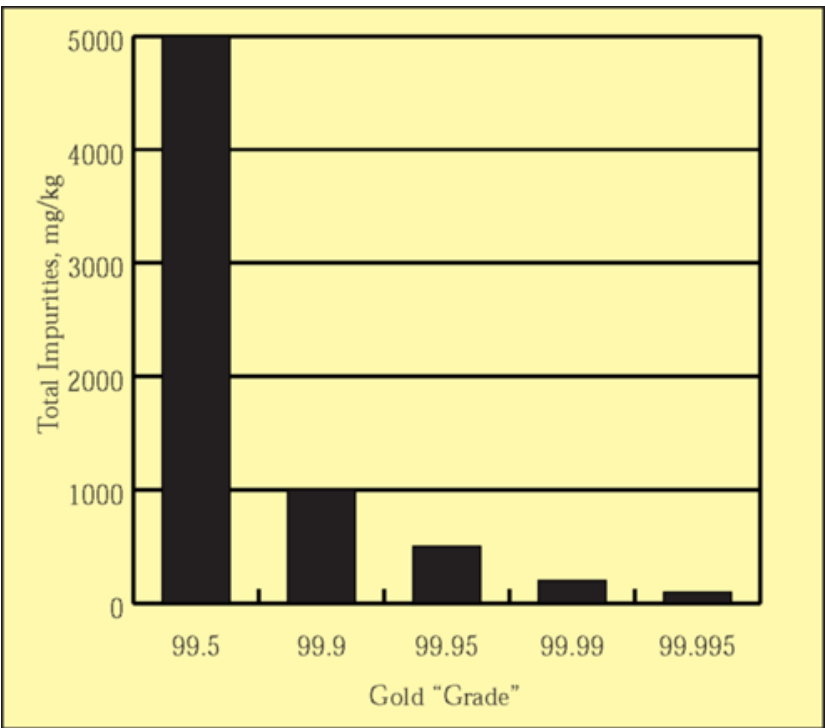

Figure 1 Total impurities as a function of gold 'grade'

elements. By this we mean, oxygen, sulfur and carbon. Chlorine, used in most gold refining processes in one form or another, is not mentioned. Again one assumes that these elements have been found historically to be irrelevant in characterizing gold or do not have a major impact on gold alloys (a potentially risky assumption in the case of chlorine which can react with all major constituents of jewelry alloys). Other elements that impact alloy properties and would be suspected to be present in gold from primary sources, yet are not included in ASTM B-562, are antimony, selenium, tellurium and mercury. Thus ASTM B-562 presents a variety of metallic elements for consideration but omits many others. To protect themselves, industrial buyers often target other elements. (In fact ASTM B-562 clearly states that, "by agreement between purchaser and manufacturer, analyses may be required and limits established for elements not specified" by ASTM B-562.)

Of the approximately one hundred elements, relatively few require measurement by industrial or commercial agreements. Of course, analyzing for all elements would be difficult and costly and serve no practical purpose. In this regard, the argument for 'indicator' elements has merit. By this, we mean selecting one element from a chemical family whose concentration serves as an indicator for other elements in the family. Thus palladium can be viewed as an 'indicator' for platinum-group metals; high palladium concentrations point to the need to check for other family members while low values indicate that other platinum-group metals are probably not present. Combining the use of 'indicators' with a knowledge of which elements may be 
present in refined gold and which may be deleterious to manufacturing operations allows the list of candidate elements to be dramatically reduced.

Nadkarni and Agarwal (1) classified gold impurities into three categories: metallic or elemental, non-metallic and radioactive. Radioactive impurities in gold, such as uranium and thorium, are important to industrial users because of the effects of small amounts of radiation on electronic components but are not generally a concern to jewelry manufacturers. We will not consider radioactive impurities further. Similarly, non-metallic impurities, for example oxide particles containing chromium or magnesium that cause problems when gold is formed into very thin wires or strips for industrial products, will not be discussed. Elemental impurities, fortunately the easiest to detect, form the most important class of impurities with regard to jewelry fabrication. Here we will consider silver (more because it serves as a convenient model for discussing mechanisms of impurity transport during refining than because of manufacturing implications), lead, iron, and silicon and other related metals. But before discussing the effect of impurities during manufacturing, it is necessary to consider methods for measuring the concentrations of these elements in gold bullion and review how small concentrations of these elements traverse the refining process.

\section{ANALYTICAL METHODS}

Fire assay, one of the most precise and robust analytical techniques developed by mankind, has little or no place in a discussion of impurities in gold bullion. Since a fire assay consists of collecting the precious metals from a particular sample into a bead and comparing the weight of that bead against the original sample weight, the technique is limited to measuring overall precious metal content. While fire assay can determine whether bullion is 995 or 999 fine, up to a limit of 999.9 fine, it cannot identify which impurities are present nor their respective concentrations. For this reason, ASTM B-562 requires a minimum gold content, performed by fire assay, only for the 99.5 grade. For higher purities, the concentrations of significant trace elements are measured and the balance assumed to be gold. Obviously when using such a method, all significant impurities must be considered, otherwise the calculated gold content will be in error. Fire assay can be used as a check.

Several techniques exist for measuring impurity levels in gold bullion. Most commonly, a sample is dissolved into solution and the concentrations of the various elements are measured by spectroscopic means. This can be done by atomic absorption spectrometry or D.C. plasma spectroscopy (2). I.C. plasma spectrometry can be used for solutions or, in some cases, can analyse a solid sample directly. The advantages of eliminating the dissolution step are twofold: (1) if an impurity does not dissolve, its concentration cannot be determined in solution; and (2) impurities from glassware and laboratory reagents do not contribute to the measurement. Other techniques that avoid dissolution are mass spectroscopy, $\mathrm{X}$-ray fluorescence and spark or arc emission techniques. Of these, mass spectroscopy has emerged as the technique of choice for high-purity materials because of its ability to measure trace concentrations of virtually all elements. This feature alone minimizes the risk of overlooking a particular element when determining gold content by difference.

While bullion producers rely on several techniques for measuring 'average' or 'bulk' concentrations of impurities in gold, other techniques are more appropriate for jewelry manufacturers. In particular, a scanning electron microscope (SEM) equipped with an EDS (Energy Dispersive Spectrometer) probe allows one to 'focus' into very specific areas on a specimen and determine 'localized' concentrations (3). If a fracture occurs, or a hard spot exists, those elements present at the point of trouble can be determined. This is crucial since deleterious elements tend to segregate along grain boundaries and lattice imperfections leading to 'localized' concentrations that are many times larger than 'bulk' concentrations. While bullion producers must rely on 'bulk' methods to characterize their homogeneous product, jewelry manufacturers must recognize that small 'bulk' concentrations can lead to highly concentrated 'localized' impurity levels.

\section{REFINING PROCESSES}

\section{Process Descriptions}

There are basically two approaches for refining gold (4). The first and oldest (dating back to the discovery of nitric acid in the Middle Ages) is dissolution followed by precipitation. Impure gold is dissolved into a chloride solution using a strong oxidant such as nitric acid. The solution is then filtered to separate undissolved or precipitated impurities (principally silver chloride) from dissolved species. After filtering, a selective reductant, generally a sulfur compound such as sodium sulfite or sulfur dioxide gas, is added to precipitate gold as a sponge. The sponge is rinsed several times, dried and melted. 
Much research has been performed on improving the dissolution/precipitation process in recent years. Besides examining a wide range of oxidants and precipitation agents, solvent extraction has been incorporated into the process. In this step, dissolved gold is selectively transferred from an impure aqueous solution into an organic phase and then returned to a relatively pure aqueous phase for reduction. Direct reduction from the organic phase is also possible. The selective action of the organic reagent rejects unwanted impurities and allows reduction to be carried out from a 'purified' process stream.

The other established refining process, and the one practiced by most diversified refineries, is chlorination followed by electrorefining. This process has been in existence, basically unchanged, for over one hundred years. During chlorination, impure gold is charged to a furnace, and after melting, chlorine gas is sparged into the bath. Chlorine bubbles, rising upwards through the molten metal, initially react with base metal impurities such as iron and zinc to form volatile metal chlorides that leave the furnace. Once the gaseous metal chlorides are removed, molten chlorides of copper and silver form and float to the surface of the melt to be removed as a slag. Given enough chlorine, essentially all the base metals and silver can be removed, resulting in gold purities of up to $99.5 \%$ if platinum-group metals are not present. (Platinumgroup metals do not react with chlorine.) At this point, however, gold begins to react with chlorine and form gaseous chlorides. To prevent gold losses, most refineries stop chlorinating well below $99.5 \%$ and pour off the product to be refined electrolytically. Chlorination is commonly known as the Miller process after one of its first practitioners.

Relatively pure gold from the chlorination furnace containing small amounts of base metals along with platinum-group metals is next cast into anodes. The anodes are immersed in a warm solution of gold chloride opposite cathodes made of titanium or thin gold strips. An electric current is forced to flow between electrodes causing gold in the anodes to dissolve into solution and gold in the solution to deposit on the cathodes. Impurities in the anodes either form insoluble particles (principally silver chloride) or dissolve into solution but do not deposit on the cathodes. Over time, soluble impurities build up in solution requiring that it be replaced. Cathode deposits from the cells are stripped (if titanium blanks are used), thoroughly rinsed and melted. Electrolytic refining of gold is known as the Wohlwill process after its inventor.
Each of the two refining schemes has its advantages and disadvantages (5). Miller/Wohlwill requires a significant capital expenditure (both for equipment and operating capital), but is capable of handling a wide diversity of incoming feedstocks. Dissolution/precipitation can be carried out at any scale at a rapid pace but is only applicable to acidsoluble feedstocks. Since both processes rely on aqueous chloride chemistry, the mechanisms by which impurities contaminate the final product are similar.

\section{Mechanisms of Contamination}

Inevitably, the principal contaminant in high purity gold is silver. Comprehensive discussions of silver as an impurity can be found in the literature (6). Other than diminishing the intrinsic value of the final product, the small concentrations of silver found in 999.9-fine gold have little deleterious effect on jewelry manufacturing processes; in most cases, much greater amounts of silver are being added anyway. (Typically, $10 \mathrm{~K}$ and $14 \mathrm{~K}$ alloys contain over 10 percent silver.) However, the mechanisms by which silver contaminates refined gold are worthy of discussion since other impurities follow similar paths; and, as a chloride salt, silver can carry with it a much less tolerable impurity, namely chloride.

In oxidizing solutions with high excess chloride concentrations, silver is soluble to a surprising degree. A typical solution at room temperature can hold over 1 $\mathrm{g} / 1 \mathrm{Ag}$ as a complexed chloride species $\mathrm{Ag}(\mathrm{Cl})_{\mathrm{X}}{ }^{1-\mathrm{x}}$ where $\mathrm{x}$ can range from 1 to 3 . Other factors further enhance silver chloride solubility, principally temperature (elevated in refining solutions to promote rapid kinetics) and aging time (silver chloride particles are freshly formed in refining solutions and as such are very amenable to dissolution). Thus silver is present as finely divided silver chloride particles and as dissolved silver chloride complexes. At least three avenues therefore exist for contamination to occur:

1 Migration/convection of particles to a porous gold surface followed by entrapment in the solid;

2 Entrainment of solution in the porous gold surface; and

3 Reduction from solution and incorporation into the lattice.

Of these, the first predominates. Cathodes from a Wohlwill operation or sponge from precipitation are always rinsed in solutions specially selected to dissolve silver chloride.

Accepting that process solutions always contain solid silver chloride particles, various strategies have been developed to prevent particle transport into the gold product. Here the leach/precipitation process 
offers advantages over electrowinning (assuming, of course, that feedstocks do not contain so much silver that dissolution is impeded by the formation of tightly adhering silver chloride, in which case, dissolution cannot be used). Leach solutions generally are allowed to cool before being passed through highly retentive filters prior to precipitation. Besides removing silver chloride, other insoluble or 'slimes' constituents are removed as well. These include platinum-group metals (rhodium, osmium and iridium). Even after filtration, silver chloride particles can precipitate out of solution because of dilution effects when gold is precipitated. In the Miller/Wohlwill process, most silver is removed during chlorination. But the small amount remaining is not captured during electrolysis by filtering solutions. Instead, quiescent or mildly stirred conditions are maintained to allow particulates to settle to the bottom of electrolytic cells. Some operations utilize porous bags to retain silver chloride slimes in the vicinity of the anode.

Any solution caught in porous cathodes or gold sponges carries with it all of its dissolved constituents. These impurities precipitate as salts during drying or melting. At that point, whether the impurity dissolves into molten bullion depends on salt stability at high temperatures and in the presence of reducing agents (for example, graphite in the crucible). While silver chloride is thermally stable, it can be reduced relatively easily into a gold matrix. Thus, most dissolved silver chloride carried out of the precipitation reactor or electrolytic cell, ends up in the final product as metallic silver. Other soluble impurities such as palladium and platinum will also be reduced to the metallic state during melting while others such as calcium and sodium will not be. Copper, found in high concentrations in dissolution liquors and electrolytes, can be captured by suitable fluxing.

The last mode of silver contamination is reduction to the metallic state in the precipitation stage or by the cathodic potential. The chemical reaction for silver chloride reduction can be written:

$$
\mathrm{AgCl}_{\mathrm{x}}^{1-\mathrm{x}}(\mathrm{aq})+\mathrm{e}^{-}=\mathrm{Ag}^{0}(\mathrm{~s})+\mathrm{x} \mathrm{Cl}^{-}(\mathrm{aq})
$$

where electrons are supplied either by the reducing agent during precipitation or at the cathode during electrorefining. Thermodynamically, this reaction should not proceed if even small concentrations of gold are present in solution, assuming a unit activity for the solid. However, silver is actually being reduced onto a gold lattice containing little silver. This additional driving force must contribute to some reduction. A detailed investigation of this mechanism would be useful but to date nothing has been reported in the open literature. Other elements may also be reduced. Lead, thallium and bismuth and mercury all act as depolarizers in gold plating baths (7). These elements form adsorbed monolayers on gold surfaces at potentials positive to those at which bulk cathodic deposition begins. Such phenomena may also occur in chloride solutions.

The rationale for solvent extraction should be apparent from this discussion. By extracting gold from leach solutions into another liquid phase, one can avoid the carry-over of impurity elements and subsequent contamination of precipitated gold. Nevertheless, small concentrations of some impurities such as silver still find a route into the final product, either by physical entrainment or coextraction.

\section{GOLD BULLION SURVEY}

To get an idea of the range of impurities found in fine gold bullion in today's market, we purchased gold grain or small bars from nine different refineries and analyzed the gold bullion by glow discharge mass spectroscopy. Refineries were selected based on the availability of their product to US jewelry manufacturers. Large, integrated facilities known to practice chlorination/electrorefining were selected along with smaller refineries which practice dissolution/precipitation. No attempt was made to make the sampling statistically meaningful. Rather, grain or bars were purchased from standard sources on a 'grab' basis - the sample grabbed by the seller was the sample analyzed. If the purchase was grain, a small amount of sample was melted in a laboratory induction furnace and poured into a pin mold. If the sample was a bar, drill samples were taken and the drillings melted in the laboratory furnace to produce a pin. (To confirm that no contamination occurred during drilling, a drill sample from one bar was compared with a sample taken with an evacuated glass tube after the entire bar was melted.) Concentrations of seventeen metallic elements were measured in the samples. Results are presented in Table 2.

Of the samples acquired, nearly 89 percent met or exceeded their hall-marked purity levels. Sample A failed. In this case, the gold grain contained over 2000 $\mathrm{mg} / \mathrm{kg}$ of various impurities. While conclusions should not be drawn about the marketplace as a whole from a non-statistical survey, this illustrates why consumers must deal with reputable sources capable of providing certified analyses of their products. 
Table 2 Concentration of impurities in bullion products from nine different precious metal refineries as measured by glow discharge mass spectroscopy. All values given in $\mathrm{mg} / \mathrm{kg}(\mathrm{ppm})$, except for gold which is given in parts per thousand

$\begin{array}{cccc}\text { Element } & \text { A } & \text { B } & \text { C } \\ \mathrm{Mg} & 0.1 & 0.2 & 0.1 \\ \mathrm{Si} & 0.6 & 0.7 & 1.0 \\ \mathrm{Cr} & 0.3 & 0.1 & 0.1 \\ \mathrm{Mn} & 0.5 & 0.2 & 0.1 \\ \mathrm{Fe} & 8.8 & 2.4 & 4.5 \\ \mathrm{Ni} & 2.7 & 0.4 & 0.1 \\ \mathrm{Cu} & 103.7 & 4.9 & 1.6 \\ \mathrm{As} & 0.2 & 0.0 & 0.0 \\ \mathrm{Zr} & 0.2 & 0.0 & 0.0 \\ \mathrm{Pd} & 4.3 & 1.3 & 1.2 \\ \mathrm{Ag} & 2300.0 & 43.2 & 57.8 \\ \mathrm{In} & 0.5 & 0.1 & 0.0 \\ \mathrm{Sn} & 13.3 & 0.4 & 0.4 \\ \mathrm{Ir} & 0.0 & 0.0 & 0.3 \\ \mathrm{Pt} & 0.1 & 0.9 & 0.3 \\ \mathrm{~Pb} & 6.2 & 2.3 & 0.1 \\ \mathrm{Bi} & 0.3 & 0.3 & 0.1 \\ \text { SUM } & 2441.7 & 57.2 & 67.8 \\ \text { Au (measured) ppt } & 997.56 & 999.94 & 999.93 \\ \text { Au (as purchased) ppt } & 999.5+ & 999.9+ & 999.9+ \\ \text { Form } & \mathrm{Grain} & \mathrm{Bar} & \mathrm{Bar} \\ & & & \end{array}$

The data in Table 2 show that, as expected, silver was the predominant impurity in all samples, at much higher concentrations than any other element. For 999.9+ fine gold, silver concentrations ranged from less than $20 \mathrm{mg} / \mathrm{kg}$ in two cases, to about $70 \mathrm{mg} / \mathrm{kg}$. For 999.5 -fine gold, silver was up to $120 \mathrm{mg} / \mathrm{kg}$. (Sample A had $2000 \mathrm{mg} / \mathrm{kg}$ ). Other elements were found at levels substantially less than $10 \mathrm{mg} / \mathrm{kg}$. Next to silver, iron and copper were the next most prevalent impurities at concentrations of about $5 \mathrm{mg} / \mathrm{kg}$. Lead was measured at approximately $1 \mathrm{mg} / \mathrm{kg}$. Other elements found at about the $1 \mathrm{mg} / \mathrm{kg}$ level were palladium, platinum and silicon.

The range of impurity concentrations from batch to batch for two different refineries is presented in Table 3. Here four different batches of 999.9-fine gold grain from each refinery were analysed separately. Variation is plainly evident but not so much as to negate the observations given above.

Lastly, for the sake of completeness, two samples were subjected to a complete elemental scan to determine if any impurities had been overlooked. The

\begin{tabular}{cccccc} 
Concentration, $\mathrm{mg} / \mathbf{k g}$ & & & & \\
$\mathrm{D}$ & $\mathrm{E}$ & $\mathrm{F}$ & $\mathrm{G}$ & $\mathrm{H}$ & $\mathrm{I}$ \\
0.1 & 0.5 & 0.3 & 0.1 & 0.5 & 0.1 \\
0.5 & 0.0 & 0.0 & 0.0 & 0.0 & 2.6 \\
0.1 & 0.5 & 0.2 & 0.2 & 0.3 & 0.6 \\
0.1 & 0.3 & 0.2 & 0.1 & 0.3 & 0.4 \\
2.4 & 4.1 & 6.8 & 3.5 & 4.0 & 1.7 \\
0.3 & 0.2 & 0.2 & 0.1 & 0.2 & 0.2 \\
1.3 & 4.3 & 0.8 & 0.9 & 1.4 & 12.4 \\
0.0 & 0.1 & 0.1 & 0.1 & 0.1 & 0.0 \\
0.0 & 0.1 & 0.9 & 0.1 & 0.2 & 0.0 \\
0.7 & 0.9 & 0.8 & 2.4 & 0.5 & 7.3 \\
55.9 & 35.5 & 40.4 & 18.5 & 115.8 & 26.3 \\
0.1 & 0.1 & 0.0 & 0.0 & 0.1 & 0.0 \\
1.2 & 0.3 & 0.2 & 0.5 & 0.6 & 0.3 \\
0.2 & 0.4 & 0.1 & 0.2 & 0.0 & 0.6 \\
0.2 & 0.6 & 0.2 & 1.2 & 0.0 & 3.6 \\
0.1 & 0.2 & 0.1 & 0.2 & 1.9 & 0.1 \\
0.3 & 0.0 & 0.1 & 0.3 & 0.6 & 0.5 \\
63.4 & 48.2 & 51.5 & 28.4 & 126.6 & 56.6 \\
999.94 & 999.95 & 999.95 & 999.97 & 999.87 & 999.94 \\
$999.5+$ & $999.9+$ & $999.9+$ & $999.9+$ & $999.5+$ & $999.9+$ \\
Bar & Grain & Grain & Grain & Grain & Grain \\
\hline & & & & &
\end{tabular}

results are presented in Table 4. Because of the need for precise standards when performing such analyses and the fact that these standards are not available for many of the elements included in Table 4, results are given as 'less than $1 \mathrm{mg} / \mathrm{kg}$ ' for elements measured at the parts per billion level. Results for nitrogen, oxygen and chlorine are not reported for similar reasons. As indicated, there are no other elements in these samples at concentrations above $1 \mathrm{mg} / \mathrm{kg}$ except those that were initially selected for analysis.

Overall, the fineness of 89 percent of the gold bullion acquired in this survey met ASTM specifications. In these samples, few elements other than gold were found in gold bullion at measurable levels. Of these impurities, silver predominated. Significant concentrations of copper, platinum, palladium, lead and, in some cases, silicon, were found. (All of these elements, except platinum, are included in ASTM B-562, more or less validating its selection of impurities.) Given that silver and copper are common alloying elements, we will only further address the other 
Table 3 Variation in impurity concentrations for bullion products from two different precious metal refineries as measured by glow discharge mass spectroscopy. All values given in $\mathrm{mg} / \mathrm{kg}(\mathrm{ppm})$, except for gold which is given in parts per thousand

\begin{tabular}{|c|c|c|c|c|c|c|c|c|}
\hline \multirow[b]{2}{*}{ Element } & \multicolumn{6}{|c|}{ Concentration, $\mathrm{mg} / \mathrm{kg}$} & \multirow[b]{2}{*}{ I3 } & \multirow[b]{2}{*}{ I4 } \\
\hline & E1 & E2 & E3 & E4 & I1 & I2 & & \\
\hline $\mathrm{Mg}$ & 0.2 & 0.4 & 0.1 & 0.5 & 0.1 & 0.0 & 0.0 & 0.1 \\
\hline $\mathrm{Si}$ & 0.0 & 0.0 & 0.4 & 0.0 & 2.6 & 0.9 & 0.7 & 1.6 \\
\hline $\mathrm{Cr}$ & 0.2 & 0.4 & 0.1 & 0.5 & 0.6 & 0.1 & 0.2 & 0.2 \\
\hline $\mathrm{Mn}$ & 0.2 & 0.3 & 0.1 & 0.3 & 0.4 & 0.1 & 0.2 & 0.2 \\
\hline $\mathrm{Fe}$ & 6.0 & 9.7 & 3.2 & 4.1 & 1.7 & 0.7 & 0.7 & 2.8 \\
\hline $\mathrm{Ni}$ & 0.2 & 0.2 & 0.1 & 0.2 & 0.2 & 0.1 & 0.1 & 0.1 \\
\hline $\mathrm{Cu}$ & 5.0 & 7.2 & 3.3 & 4.3 & 12.4 & 4.5 & 6.9 & 7.4 \\
\hline As & 0.1 & 0.2 & 0.1 & 0.1 & 0.0 & 0.0 & 0.0 & 0.0 \\
\hline $\mathrm{Zr}$ & 0.1 & 0.2 & 0.1 & 0.1 & 0.0 & 0.0 & 0.1 & 0.0 \\
\hline $\mathrm{Pd}$ & 1.2 & 1.5 & 0.7 & 0.9 & 7.3 & 3.4 & 4.5 & 3.3 \\
\hline $\mathrm{Ag}$ & 32.4 & 42.1 & 18.8 & 35.5 & 26.3 & 72.5 & 49.8 & 69.9 \\
\hline In & 0.1 & 0.1 & 0.0 & 0.1 & 0.0 & 5.8 & 3.8 & 0.1 \\
\hline Sn & 0.3 & 0.3 & 0.2 & 0.3 & 0.3 & 0.2 & 0.2 & 0.3 \\
\hline Ir & 0.5 & 0.5 & 0.4 & 0.4 & 0.6 & 0.3 & 1.2 & 1.1 \\
\hline $\mathrm{Pt}$ & 0.8 & 1.0 & 0.7 & 0.6 & 3.6 & 1.7 & 2.5 & 2.0 \\
\hline $\mathrm{Pb}$ & 0.4 & 0.1 & 0.1 & 0.2 & 0.1 & 0.0 & 0.0 & 0.0 \\
\hline $\mathrm{Bi}$ & 0.3 & 0.8 & 0.3 & 0.0 & 0.5 & 0.3 & 0.5 & 0.3 \\
\hline SUM & 48.1 & 65.2 & 28.7 & 48.2 & 56.6 & 90.9 & 71.4 & 89.3 \\
\hline $\mathrm{Au}$ (measured) ppt & 999.95 & 999.93 & 999.97 & 999.95 & 999.94 & 999.91 & 999.93 & 999.91 \\
\hline $\mathrm{Au}$ (as purchased) ppt & 999.9+ & 999.9+ & $999.9+$ & 999.9+ & $999.9+$ & $999.9+$ & $999.9+$ & $999.9+$ \\
\hline Form & Grain & Grain & Grain & Grain & Grain & Grain & Grain & Grain \\
\hline
\end{tabular}

three significant contaminants, lead, iron and silicon, which are known to have deleterious effects during manufacturing.

\section{EFFECTS OF IMPURITIES}

Given that measurable quantities of lead, iron and silicon are found in most bullion products, it is appropriate to review at what concentration levels these elements begin causing problems during the manufacturing process.

\section{Lead}

Lead is one of the most (if not the most) detrimental of bullion impurities in applications requiring mechanical working and high ductility. Rose (8) noted as early as 1894 that "less than 0.1 percent bismuth, tellurium or lead renders the gold brittle, owing to the distribution of $\mathrm{Bi}, \mathrm{Au}_{\mathrm{T}} \mathrm{e}_{3}$, or $\mathrm{Au}_{2} \mathrm{~Pb}$ between the grains." Rose referred to Nowack (9) who showed that at 600 $\mathrm{mg} / \mathrm{kg}$ lead, both a $10 \%$ copper-gold alloy and pure gold are unrollable but that additions of $50 \mathrm{mg} / \mathrm{kg}$ had no effect. Even so, many manufacturers set $50 \mathrm{mg} / \mathrm{kg}$ as their upper limit for acceptable lead concentrations. Without question, the concentration at which lead causes embrittlement is low, probably less than $100 \mathrm{mg} / \mathrm{kg}$.

Figures 2 and 3 present visual proof of the effect of lead on gold alloys. Figure 2 shows an SEM micrograph of a gold-lead compound at the grain boundary of $14 \mathrm{~K}$ white gold. In this case, the average concentration of lead in the sample was $400 \mathrm{mg} / \mathrm{kg}$. Figure 3 shows another example of lead segregation at grain boundaries. Here, the light-colored particles are gold-lead precipitates covering the surface of a grain exposed after a fracture occurred in a $14 \mathrm{~K}$ alloy.

\section{Iron}

From a solubility viewpoint, iron should not segregate in gold alloys. Alloys containing up to 25 percent iron have been used for jewelry in Europe. Rose (8) noted that additions of even more than 1 percent iron have only a slight effect on the rolling properties of gold. The phase diagram for gold-iron bears this out. 
Table 4 Concentration ranges for elements detected in gold bullion samples by glow discharge mass spectroscopy

\begin{tabular}{|c|c|c|c|c|c|}
\hline \multicolumn{6}{|c|}{ Concentration, $\mathrm{mg} / \mathrm{kg}$} \\
\hline & Sample & & & Sample & \\
\hline$<1$ & $1-10$ & $>10$ & $<1$ & $1-10$ & $>10$ \\
\hline $\mathrm{Be}, \mathrm{B}$ & $\mathrm{Si}$ & Li & $\mathrm{Li}, \mathrm{Be}$ & $\mathrm{Ti}$ & $\mathrm{Ag}$ \\
\hline $\mathrm{Mg}, \mathrm{Al}$ & P & $\mathrm{Na}$ & $\mathrm{B}, \mathrm{Na}$ & $\mathrm{Cu}$ & \\
\hline $\mathrm{Cl}, \mathrm{K}$ & $\mathrm{Ti}$ & $\mathrm{Cu}$ & $\mathrm{Mg}, \mathrm{Al}$ & Ru & \\
\hline $\mathrm{Ca}_{\mathrm{a}} \mathrm{Sc}$ & $\mathrm{Fe}$ & $\mathrm{Ag}$ & $\mathrm{Si}, \mathrm{P}$ & $\mathrm{Pd}$ & \\
\hline $\mathrm{V}, \mathrm{Cr}$ & $\mathrm{Zn}$ & & $\mathrm{Cl}, \mathrm{K}$ & Ir & \\
\hline $\mathrm{Mn}, \mathrm{Co}$ & Ga & & $\mathrm{Ca}, \mathrm{Sc}$ & $\mathrm{Pt}$ & \\
\hline $\mathrm{Ni}, \mathrm{Ge}$ & $\mathrm{Pd}$ & & $\mathrm{V}, \mathrm{Cr}$ & & \\
\hline As, Br & $\mathrm{Pt}$ & & $\mathrm{Mn}, \mathrm{Fe}$ & & \\
\hline $\mathrm{Se}, \mathrm{Rb}$ & $\mathrm{Pb}$ & & $\mathrm{Co}, \mathrm{Ni}$ & & \\
\hline $\mathrm{Sr}, \mathrm{Y}$ & & & $\mathrm{Zn}, \mathrm{Ga}$ & & \\
\hline $\mathrm{Zr}, \mathrm{Nb}$ & & & $\mathrm{Ge}, \mathrm{As}$ & & \\
\hline Mo, Ru & & & $\mathrm{Br}, \mathrm{Se}$ & & \\
\hline $\mathrm{Rh}, \mathrm{Cd}$ & & & $\mathrm{Rb}, \mathrm{Sr}$ & & \\
\hline $\ln , S_{n}$ & & & $\mathrm{Y}, \mathrm{Zr}$ & & \\
\hline $\mathrm{Sb}, \mathrm{I}$ & & & $\mathrm{Nb}, \mathrm{Mo}$ & & \\
\hline $\mathrm{Te}, \mathrm{Cs}$ & & & $\mathrm{Rh}, \mathrm{Cd}$ & & \\
\hline $\mathrm{Ba}, \mathrm{La}$ & & & In, Sn & & \\
\hline $\mathrm{Ce}, \mathrm{Pr}$ & & & $\mathrm{Sb}, 1$ & & \\
\hline $\mathrm{Nd}$, Eu & & & $\mathrm{Te}, \mathrm{Cs}$ & & \\
\hline $\mathrm{Sm}, \mathrm{Gd}$ & & & $\mathrm{Ba}, \mathrm{La}$ & & \\
\hline Tb, Dy & & & $\mathrm{Ce}, \mathrm{Pr}$ & & \\
\hline $\mathrm{Ho}, \mathrm{Er}$ & & & $\mathrm{Nd}$, Eu & & \\
\hline$T m, Y b$ & & & $\mathrm{Sm}, \mathrm{Gd}$ & & \\
\hline $\mathrm{Lu}, \mathrm{Hf}$ & & & Tb, Dy & & \\
\hline $\mathrm{Ta}, \mathrm{W}$ & & & $\mathrm{Ho}, \mathrm{Er}$ & & \\
\hline $\mathrm{Re}, \mathrm{Os}_{\mathrm{s}}$ & & & $\mathrm{Tm}, \mathrm{Yb}$ & & \\
\hline $\mathrm{Ir}, \mathrm{Hg}$ & & & $\mathrm{Lu}, \mathrm{Hf}$ & & \\
\hline $\mathrm{TI}, \mathrm{Bi}$ & & & $\mathrm{Ta}, \mathrm{W}$ & & \\
\hline$T h, U$ & & & $\mathrm{Re}, \mathrm{O}_{\mathrm{s}}$ & & \\
\hline & & & $\mathrm{Hg}, \mathrm{Tl}$ & & \\
\hline & & & $\mathrm{Pb}, \mathrm{Bi}$ & & \\
\hline & & & Th, U & & \\
\hline
\end{tabular}

However, as anyone who has ever tried to prepare gold standards containing a small amount of iron knows, it is not a trivial matter to add $100 \mathrm{mg} / \mathrm{kg}$ iron to pure gold and end up with a homogeneous alloy. While iron should dissolve into pure gold from a thermodynamic standpoint, its relatively high melting point makes the addition of small amounts of iron to gold difficult. Conversely, small amounts of iron can solidify in casting alloys, causing 'hard spots', if conditions are right.
Figure 4 demonstrates this point. Shown at $144 \mathrm{X}$ magnification is a hard spot on the surface of a $10 \mathrm{~K}$ casting ring. An EDS analysis showed that iron was present in the alloy along with boron. Figures 5 and 6 give further evidence of iron inclusions. Figure 5 shows the surface of a casting at low magnification while Figure 6 , at higher magnification, indicates iron particles as dark spots in the alloy matrix. Thus iron, when crudely added to gold alloys, can lead to surface imperfections and hard spots. However, the small concentrations of iron found in gold bullion are already dissolved in gold and unless another element is added to the mixture that would cause iron to coprecipitate, such phenomena are unlikely.

\section{Silicon}

A classic example of the insolubility of one element in the solid matrix of another is the gold-silicon system. There is practically no solubility of silicon in gold. It has been shown that silicon tends to segregate as separate particles in gold at levels as low $200 \mathrm{mg} / \mathrm{kg}$ (10). Figure 7 presents an SEM micrograph from this work showing black specks of segregated silicon whose 'bulk' concentration was measured to be $200 \mathrm{mg} / \mathrm{kg}$. Levels of silicon above $200 \mathrm{mg} / \mathrm{kg}$ typically result in the formation of a gold-silicon eutectic at grain boundaries. The segregation of the eutectic at the boundaries makes gold extremely brittle and can cause problems during soldering operations (11).

Silicon is commonly added to karat gold castings as a brightening agent. Occasionally, however, some castings exhibit 'hard spots', a defect typically associated with silicon segregation. Figure 8 shows a hard spot consisting of segregated particles of silicon. This type of casting defect was found in the cross section of a $10 \mathrm{~K}$ yellow ring.

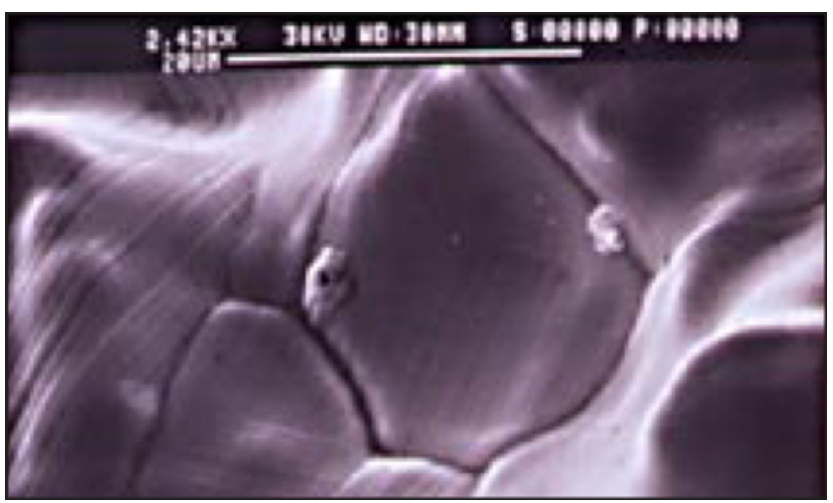

Figure 2 SEM micrograph of lead segregation at the grain boundaries of a continuously cast $14 \mathrm{~K}$ white gold. Average lead concentration measured at $400 \mathrm{mg} / \mathrm{kg}$ by atomic absorption spectroscopy $\left(2,420_{X}\right.$ magnification) 


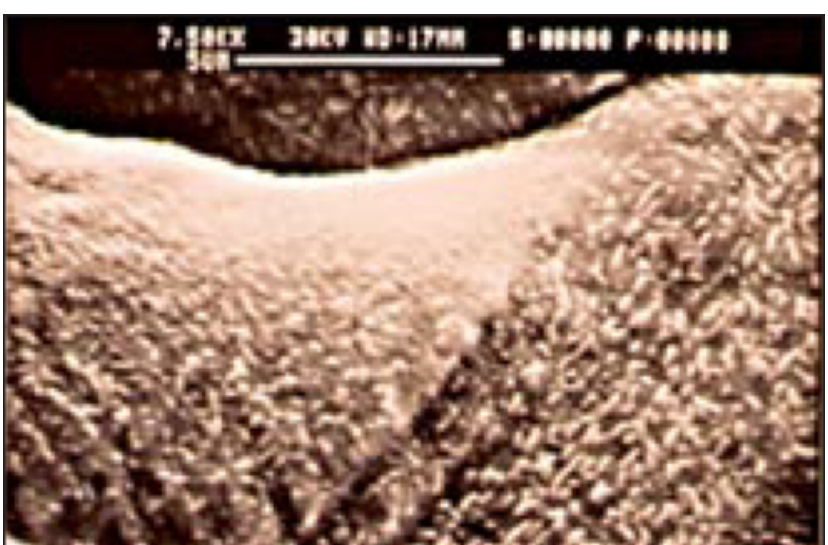

Figure 3 SEM micrograph of the surface of a grain exposed after fracture occurred in a $14 \mathrm{~K}$ alloy. Light areas represent lead precipitate $\left(7,500_{X}\right.$ magnification)

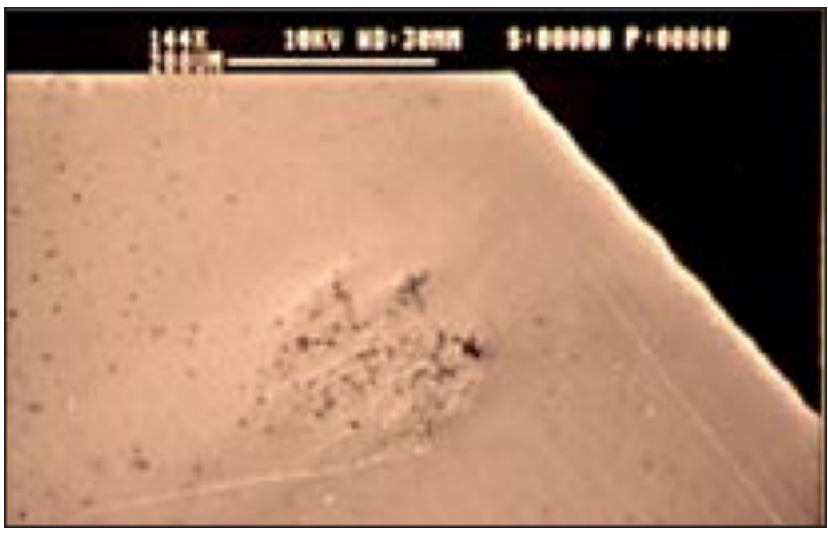

Figure 4 SEM micrograph of the surface of a $10 K$ casting ring showing a hard spot caused by iron and boron (144x magnification)

Silicon can also combine with other elements in the gold alloy and precipitate as a compound at grain boundaries. The segregation of silicon and iridium is shown in Figure 9. In this micrograph of a $14 \mathrm{~K}$ yellow ring, the dark areas show silicon and the bright areas iridium. This type of segregation appeared as a white discoloration on the cast surface. Silicon can also combine with nickel, forming nickel silicide in $10 \mathrm{~K}$ white castings (10). Once again, nickel silicide forms at the boundaries between the alloy grains leading to embrittlement of the casting.

\section{CONCLUSIONS}

In this paper, we have reviewed the various issues associated with impurities in gold bullion. After discussing the two basic refining processes in use

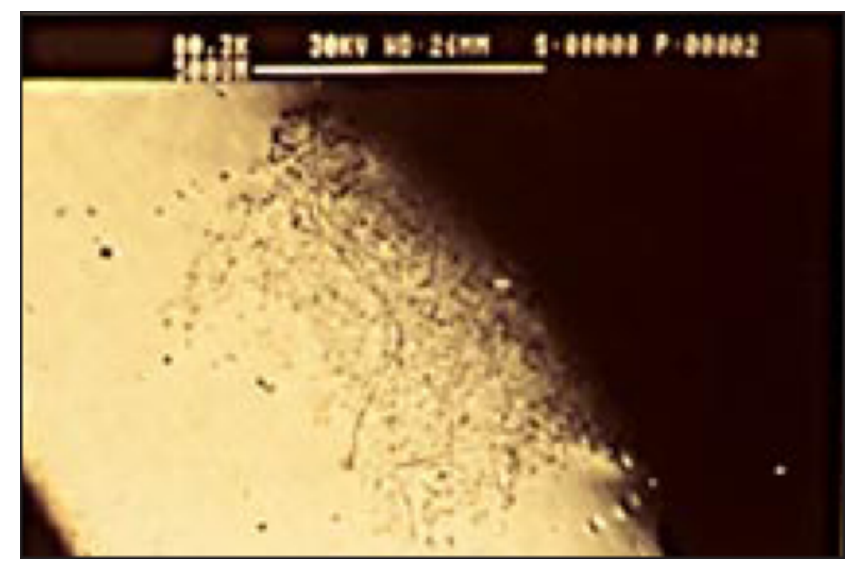

Figure 5 SEM micrograph of the surface of a gold alloy showing iron inclusions ( $80.3 \mathrm{x}$ magnification)

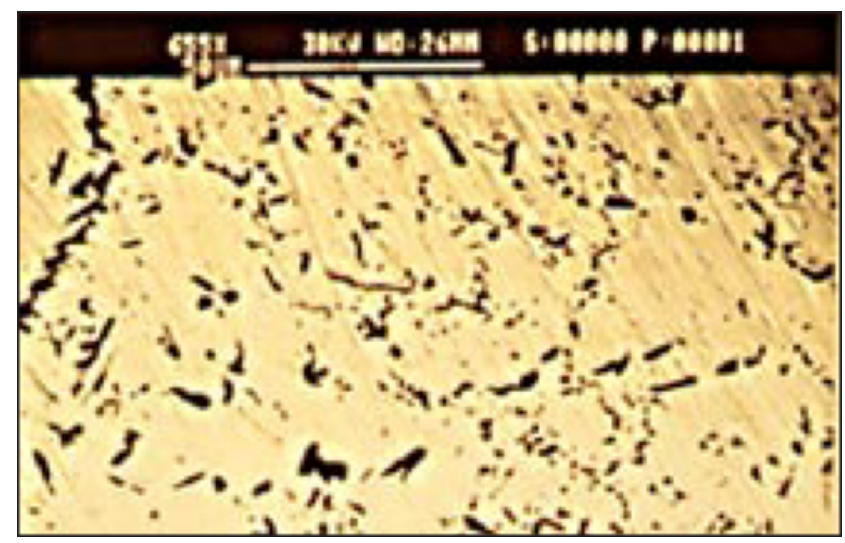

Figure 6 SEM micrograph of the iron inclusions shown in Figure 5 at higher magnification. Dark areas represent iron particles (655 $x$ magnification)

today, we described how it is possible that small amounts of some elements can traverse the purification sequence and contaminate fine gold. Several mechanisms exist for contamination to occur and one refining process, per se, does not have a particular advantage over the other with regard to purity. If properly operated, both the classical chlorination/electrorefining and dissolution /precipitation refining processes result in high-quality gold. If operated improperly, neither does. We then surveyed the output from nine different refineries that produce gold grain and bars commonly used by jewelry manufacturers. Using glow discharge mass spectroscopy, we found that in nearly 89 percent of the samples acquired in our survey, the gold bullion met or exceeded hallmarked purities. The distribution of impurities was remarkably similar regardless of refining technique. As expected the major impurity in 


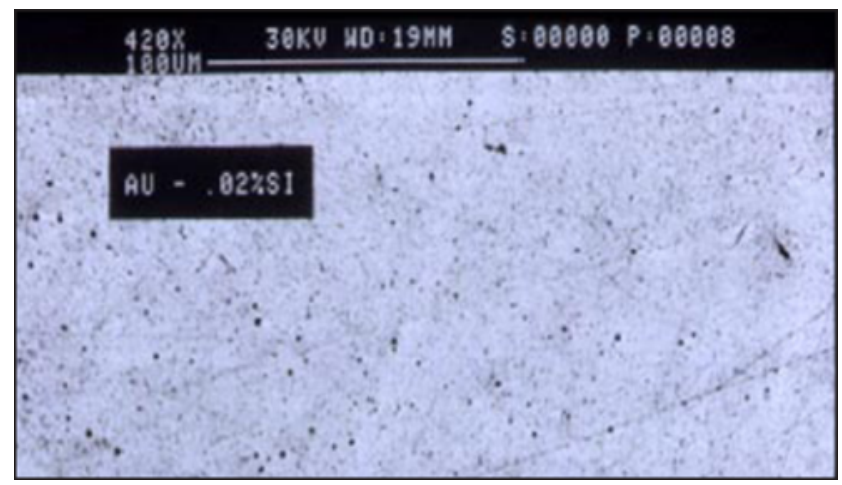

Figure 7 SEM micrograph of silicon particles dispersed in gold matrix. Average concentration of silicon measured at $200 \mathrm{mg} / \mathrm{kg}$ (424x magnification)

fine gold was silver. Other elements found in significant concentrations were iron, copper, lead and silicon.

Of the elements found in refined gold, lead and iron typically have the most potential to disrupt the jewelry manufacturing process. We reviewed how lead, iron and silicon, as well as combinations of silicon with other elements, can lead to embrittlement and hard spots. Because these impurities segregate at grain boundaries, low levels measured in 'bulk' techniques can be misleading. It is only by carefully controlling the purity of all constituents in a jewelry alloy, including additives, that the quality of the final product can be assured. In this respect, having certified analyses of all materials, including fine gold, minimizes the risks and simplifies investigations of problems should they arise.

\section{ABOUT THE AUTHORS}

David Kinneberg is Director of Research and Development and Stephen Williams is Vice President of Sales and Marketing in Metalor Refining Corporation, USA; D.P. Agarwal is Vice President of Leach and Garner Company. They each have a special interest in the production of pure gold.

\section{REFERENCES}

1 R.M. Nadkarni and D.P. Agarwal, 'Impurities in Gold: Pedigree versus Specification', Precious Metals 1988, Int. Precious Metals Inst., Allentown, PA, p.283

2 A. Savolainen, 'Modern Gold Assaying', Precious Metals 1988, Int. Precious Metals Inst., Allentown, PA, p. 55

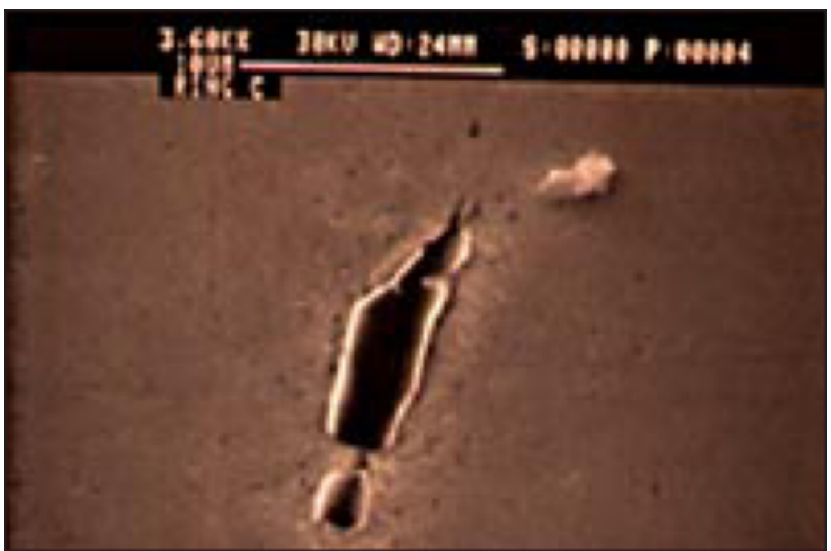

Figure 8 SEM micrograph of silicon segregation at the grain boundaries of a $10 \mathrm{~K}$ alloy $(3,360 x$ magnification $)$

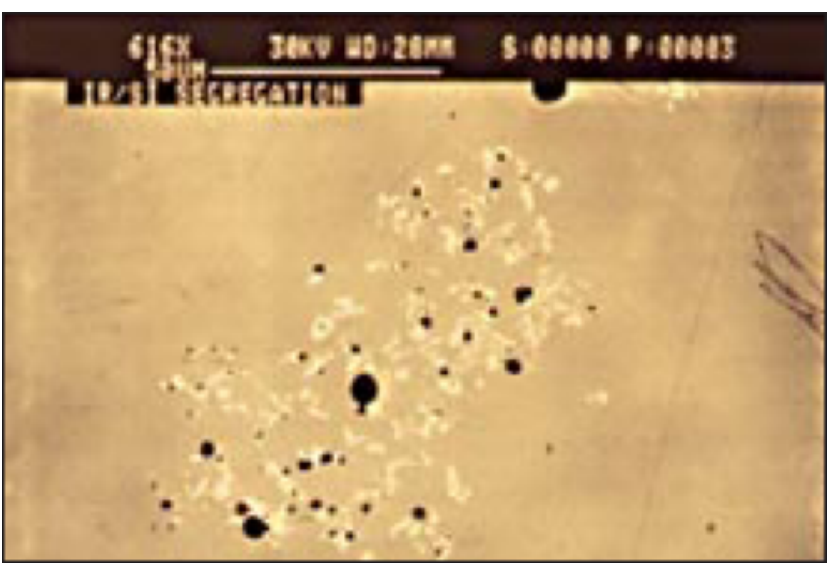

Figure 9 SEM micrograph of iridium/silicon segregation in a gold alloy (616 $x$ magnification)

3 D.P. Agarwal and G. Raykhtsaum, 'Materials Characterization and Failure Analysis in Jewelry Scientific Instrumentation', presented at the Santa Fe Symposium on Jewelry Manufacturing Technology, 1992

4 R.M. Nadkarni, D.J. Kinneberg, M.B. Mooiman and P. Cettou, 'Precious Metals Processing', Elliott Symposium, Iron and Steel Society, Warrendale P.A. 1990, p.96

5 D.J. Kinneberg, M.B. Mooiman and W.D. Müller, 'Gold Refining - Past, Present and Future', Precious Metals 1996, Int. Precious Metals Inst,, Allentown, PA, 1996, p.433

6 D. Schneller, 'Silver Contamination in Fine Gold', presented at 'Refining and Recovery of Precious Metals', Int, Precious Metals Inst., Los Angeles, CA, March 1986

7 J.D. McIntyre and W.F. Peck, Jr., Electrodeposition of Gold', J. Electrochem. Soc, 1976, $123(12), 1800$

8 T.K. Rose and WA.C. Newman, 'The Metallurgy of Gold', Reprint of 7th Ed., Met Chem Research, Inc., Boulder, CO, 1986, p.36

9 Z. Nowack, Z. anorg. Chem, 1926, 154, 395

10 G. Raykhtsaum and D.P. Agarwal, 'Gold in Jewelry', Precious Metals 1993, Int. Precious Metals Inst., Allentown, PA, p.169

11 G. Raykhtsaum and D.P. Agarwal, 'Defects in Castings and Wrought Products Associated with the Phenomenon of Segregation in Karat Golds', presented at the Santa Fe Symposium on Jewelry Manufacturing Technology, 1993 